\title{
Effects of Introduced Materials in the Drift Scale Test
}

R.L. Jones, L.D. DeLoach

January 11, 2002

U.S. Department of Energy

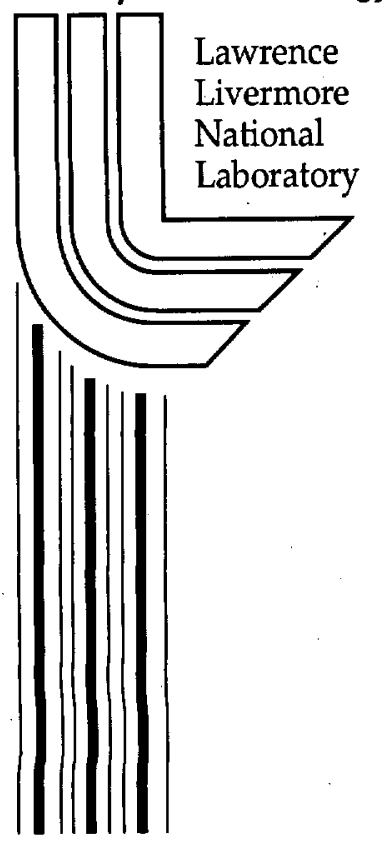




\section{DISCLAIMER}

This document was prepared as an account of work sponsored by an agency of the United States Government. Neither the United States Government nor the University of California nor any of their employees, makes any warranty, express or implied, or assumes any legal liability or responsibility for the accuracy, completeness, or usefulness of any information, apparatus, product, or process disclosed, or represents that its use would not infringe privately owned rights. Reference herein to any specific commercial product, process, or service by trade name, trademark, manufacturer, or otherwise, does not necessarily constitute or imply its endorsement, recommendation, or favoring by the United States Government or the University of California. The views and opinions of authors expressed herein do not necessarily state or reflect those of the United States Government or the University of California, and shall not be used for advertising or product endorsement purposes.

This work was performed under the auspices of the U. S. Department of Energy by the University of California, Lawrence Livermore National Laboratory under Contract No. W-7405-Eng-48.

This report has been reproduced directly from the best available copy.

Available electronically at http://www.doe.gov/bridge

Available for a processing fee to U.S. Department of Energy

and its contractors in paper from

U.S. Department of Energy

Office of Scientific and Technical Information

P.O. Box 62

Oak Ridge, TN 37831-0062

Telephone: (865) 576-8401

Facsimile: (865) 576-5728

E-mail: reports@adonis.osti.gov

Available for the sale to the public from

U.S. Department of Commerce

National Technical Information Service

5285 Port Royal Road

Springfield, VA 22161

Telephone: (800) 553-6847

Facsimile: (703) 605-6900

E-mail: orders@ntis.fedworld.gov

Online ordering: http://www.ntis.gov/ordering.htm

OR

Lawrence Livermore National Laboratory

Technical Information Department's Digital Library

http://www.llnl.gov/tid/Library.html 


\section{Effects of Introduced Materials in the Drift Scale Test}

Prepared for:

U.S. Department of Energy

Yucca Mountain Site Characterization Office

P.O. Box 30307

North Las Vegas, Nevada 89036-0307

Prepared by:

Robert L. Jones, Laura D. DeLoach

Under Contract Number

DE-AC08-01NV12101 


\section{Effects of Introduced Materials in the Drift Scale Test}

\section{Summary and Conclusions}

Water samples previously acquired from superheated $\left(>140^{\circ} \mathrm{C}\right)$ zones within hydrological test boreholes of the Drift Scale Test (DST) show relatively high fluoride concentrations ( $5-66 \mathrm{ppm})$ and low $\mathrm{pH}(3.1-3.5)$ values. In these high temperature regions of the rock, water is present as superheated vapor only-liquid water for sampling purposes is obtained during the sampling process by cooling. Based on data collected to date, it is evident that the source of the fluoride and low $\mathrm{pH}$ is from introduced man-made materials (Teflon ${ }^{\mathrm{TM}}$ and/or Viton ${ }^{\mathrm{TM}}$ fluoroelastomer) used in the test. The test materials may contribute fluoride either by degassing hydrogen fluoride $(\mathrm{HF})$ directly to produce trace concentrations of $\mathrm{HF}$ gas $(\sim 0.1 \mathrm{ppm})$ in the high temperature steam, or by leaching fluoride in the sampling tubes after condensation of the superheated steam. HF gas is known to be released from Viton ${ }^{T M}$ at high temperatures (Dupont Dow Elastomers L.L.C., Elkton, MD, personal communication) and the sample water compositions indicate near stoichiometric balance of hydrogen ion and fluoride ion, indicating dissolution of HF gas into the aqueous phase.

These conclusions are based on a series of water samples collected to determine if the source of the fluoride is from the degradation of materials originally installed to facilitate measurements. Analyses of these water samples show that the source of the fluoride is the introduced materials, that is the Viton ${ }^{\mathrm{TM}}$ packers used to isolate test zones and/or Teflon ${ }^{\mathrm{TM}}$ tubing used to draw water and steam from the test zones. In particular, water samples collected from borehole (BH) 72 at high temperatures $\left(-170^{\circ} \mathrm{C}\right)$ prior to introduction of any Viton ${ }^{\mathrm{TM}}$ or Teflon ${ }^{\mathrm{TM}}$ show $\mathrm{pH}$ values (4.8 to 5.5) and fluoride concentrations well below $1 \mathrm{ppm}$ over a period of six months. These characteristics are typical of condensing DST steam that contains only some dissolved carbon dioxide generated by water-mineral-gas reactions in the rock. With the introduction of the Viton ${ }^{\mathrm{TM}}$ packer materials and Teflon ${ }^{\mathrm{TM}}$ sampling tube in $\mathrm{BH} 72$, the water samples show $\mathrm{pH}$ values drop to 3.8 , while fluoride rises to $2.4 \mathrm{ppm}$ within three days. After nine days, the $\mathrm{pH}$ values reach as low as 3.4 and fluoride concentrations rise as high as $7.5 \mathrm{ppm}$ in the collected samples. The background information describing the fluoride issue and a summary of the water collection activities along with the analytical results are provided below.

The results of the field test confirm the hypothesis that the source of the fluoride in specific samples from the DST is the introduced test materials (i.e. Viton ${ }^{\mathrm{TM}}$ and/or Teflon ${ }^{\mathrm{TM}}$ ). This is positive from the perspective of repository performance, particularly waste package and drip shield degradation behavior, as deleterious introduced materials would be avoided in an operating repository. Ongoing laboratory testing to be completed in January 2002, and additional testing in $\mathrm{BH} 72$ and $\mathrm{BH} 55$ will address further details, such as the specific material introducing the fluorine and the material breakdown process.

\section{Background}

One important objective of the Drift Scale Test was to acquire and study samples of water from the hydrology boreholes over time. Steam samples were never considered important for chemical

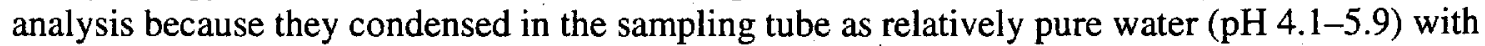
small amounts of dissolved $\mathrm{CO}_{2}$. In general, the condensed steam contains very low dissolved solids and does not indicate a reaction of water with minerals present in the rock. As the boiling front approaches a test borehole, water is driven ahead of the drying front until the front passes. 
Then, the only moisture present in the above-boiling rock regions is water vapor (steam) passing through the fracture system. As regions of the hydrology boreholes reached temperatures $40^{\circ}$ above the boiling temperature, the vapor samples drawn from these regions condensed to water samples that exhibited lower $\mathrm{pH}$ and higher dissolved solids. These compositions are not characteristic of the clean water condensed from steam in some of the lower temperature (but still above boiling) boreholes.

As shown in Figure 1, the hottest hydrologic boreholes (BH60, BH77, and BH186) in the Drift Scale Test (DST) were drilled from the Access/Observation Drift to a length of about $40 \mathrm{~m}$ to pass under the Heated Drift. These boreholes slope downward, passing within a meter of the wing heater boreholes (Figure 1), finally terminating below and beyond the Heated Drift. The hydrologic boreholes were instrumented prior to the start of the heating phase in 1997 with hardware installed to accommodate various thermal-hydrologic measurements. The measurements required the use of inflatable packers to isolate test zones and multiple Teflon ${ }^{\mathrm{TM}}$ (PTFE) tubes that passed through the packers allowing access to accumulated water or steam.

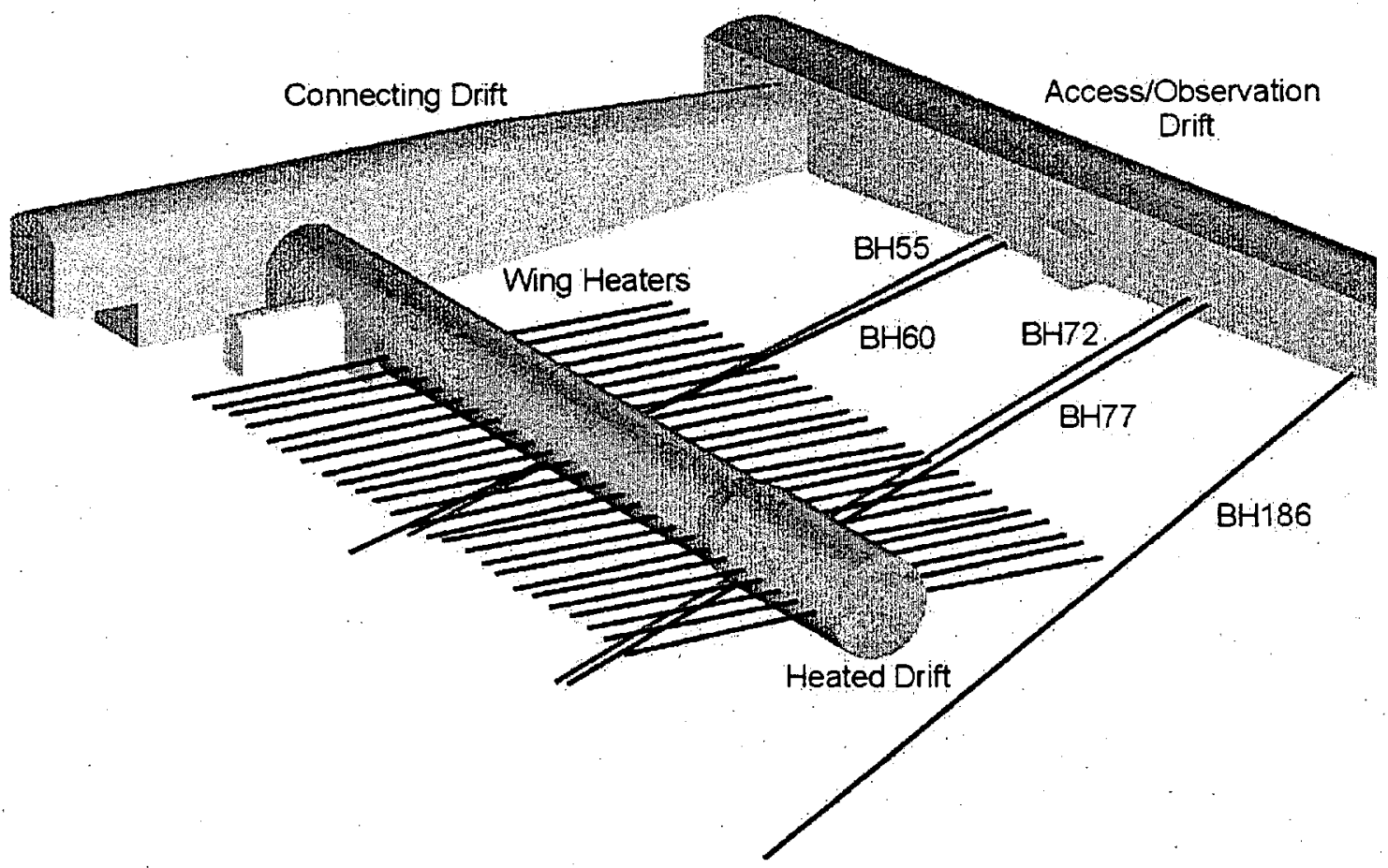

Figure 1. 3-Dimensional view of the Drift Scale Test showing the hydrology boreholes (blue) that contain Viton ${ }^{\mathrm{TM}}$ packers, wing heater boreholes (red), and SEAMIST ${ }^{\mathrm{TM}}$ holes (green). 
Several of the packers in these boreholes have failed over the past four years, possibly due to the roughness of the boreholes, the sustained high temperature environment, or chemical degradation of the material. BH60 contained four packers at depths of $4.6 \mathrm{~m}, 10.7 \mathrm{~m}, 22.0 \mathrm{~m}$, and $28.1 \mathrm{~m}$ from the collar. The three deepest packers that were nearest to the wing heaters contain Viton ${ }^{\mathrm{TM}}$, whereas the shallowest packer is Neoprene ${ }^{\mathrm{TM}}$ based. All three of the Viton ${ }^{\mathrm{TM}}$ packers in BH60 have deflated. BH77 contains three packers, two of which contain Viton ${ }^{\mathrm{TM}}$. Only the deepest packer, at a depth of $17.1 \mathrm{~m}$, has deflated. BH186 has the same packer configuration as BH60; however, none have failed to date. Viton ${ }^{\mathrm{TM}}$ was chosen as the most suitable packer material because it was reported by the manufacturer to withstand temperatures up to $200^{\circ} \mathrm{C}$.

\section{Testing Strategy}

Water samples previously acquired from superheated $\left(>140^{\circ} \mathrm{C}\right)$ zones within hydrological test boreholes of the Drift Scale Test (DST) show relatively high fluoride concentrations $(5-66 \mathrm{ppm})$ and low $\mathrm{pH}(3.1-3.5)$ values. Discussions were held among members of the Thermal Test Team to devise an appropriate strategy that would test two competing hypotheses; the source of the fluoride in the samples is introduced materials or the source is the host rock itself. One proposal was to remove the potential contaminants (Viton ${ }^{\mathrm{TM}}$ and Teflon ${ }^{\mathrm{TM}}$ ) from the high temperature boreholes, BH60 and BH77, and subsequently sample the "clean" boreholes for comparison. Because the length of the heating phase and the highest temperatures during the DST were considerable, it was believed that packer deformation had occurred making their removal difficult. The alternative to removing the proposed contaminants from BH60 and BH77 would be to start with a Viton ${ }^{T M}$ and Teflon ${ }^{T M}$ free borehole and introduce the suspected contaminants. Sampling of the boreholes would have to be done before materials introduction to characterize the uncontaminated system, and after the materials were introduced to see if the high fluoride signal was then generated.

\section{SEAMIST ${ }^{\mathrm{Tm}}$ Boreholes}

For the comparative field study, the best candidate boreholes were considered to be in arrays adjacent to the hydrology (HYD) borehole arrays and to be intersecting essentially the same temperature field. For this reason, BH72 and BH55, both from the SEAMIST ${ }^{\mathrm{TM}}$ instrumented Chemical (CHE) arrays were selected. These holes were nearly parallel to $\mathrm{BH} 77$ and $\mathrm{BH} 60$, respectively, and they were in close proximity to wing heaters.

The CHE boreholes were, by design, the primary system in the DST for sampling liquids and gases providing closely spaced sampling at discrete locations. (The HYD boreholes served for air permeability testing first and as a fluid-sampling system second). As designed for use in the DST, SEAMIST ${ }^{\mathrm{TM}}$ consisted of two inflatable, extruded-silicon rubber liners positioned side-byside. One liner was equipped with Teflon ${ }^{\mathrm{TM}}$ tubing for gas sampling. The second liner was equipped with highly-absorbent pads.

Except for a few chips of silicon nubber liner, the SEAMIST ${ }^{\mathrm{TM}}$ system from BH72 was extracted last spring to allow for side-wall drilling operations. What materials remained were pushed to the bottom of the hole by the side-wall drill bit. The SEAMIST ${ }^{\mathrm{TM}}$ system was removed from BH55 to support the HF field experiment. Unfortunately, when field technicians pulled the liner, it broke off half-way into the hole. Previous experiences with the SEAMIST liner manipulations, however, demonstrate that the strength of the Teflon ${ }^{\mathrm{TM}}$ tubing is considerably greater than their point of attachment to the liner. It is unlikely therefore, that any of the tubing remained after the 
liner removal effort. A drill rig was employed to clear the remaining liner materials by pushing them to the bottom of BH55.

\section{Experimental Method}

The HF field experiment included characterizing BH55 and BH72 to locate accessible sample collection zones with temperatures above $140^{\circ} \mathrm{C}$ while containing enough vapor to draw samples. On November $8,2001, \mathrm{BH} 72$ was characterized using a thermocouple and Tygon ${ }^{\mathrm{TM}}$ sampling $^{2}$ tube clamped to a six-foot length of titanium pipe to form a probe. Temperature readings beginning from the collar were recorded at six-foot intervals, after the addition of each subsequent section of pipe. This characterization revealed that $\mathrm{BH} 72$ was a good candidate for further experimentation. Not only were temperatures comparable with those measured in BH60, it also produced abundant water vapor. The hottest temperature zone, which measures above $170^{\circ} \mathrm{C}$, was found to be in the 78 to 84 -foot depth interval. As the probe was positioned there, a $50 \mathrm{~mL}$ sample of condensed steam was collected through the Tygon ${ }^{\mathrm{TM}}$ tubing in about 25 minutes. On June 28, 2001, a similar method was used to collect a sample from BH72; however, no temperature measurements were taken. Analytical results from that sample are included below.

Characterization of BH55 proceeded, but only after the torn SEAMIST ${ }^{\mathrm{M}}$ liner was pushed down in the borehole to a depth of $\sim 115 \mathrm{ft}$. To that depth, BH55 was characterized using the method employed in $\mathrm{BH} 72$ to measure temperature and to extract water vapor. However, the initial characterization of this borehole demonstrated clearly that it was a less viable location for the field experimentation as planned. First, during the temperature survey the hottest interval encountered was just above $140^{\circ} \mathrm{C}$, which was the lower end for temperatures associated with any of the fluoride-rich condensates collected in BH60 and BH77. Second, sampling was less efficient than previously encountered. Efforts to collect a sample from BH55 were extraordinary when compared to the typical DST water collection process. Only after a cold trap was used in the sampling line and pumping was allowed to continue did a 4-mL sample collect. The fact that the gas sampled contained much less moisture than other nearby boreholes suggested a significant fracture network that allowed air communication between BH55 and the Access/Observation Drift, Heated Drift, or adjacent boreholes. Additionally, during the temperature profiling a $3{ }^{\circ} \mathrm{C}$ drop was noted at a point 18 feet from the collar. For these reasons, the decision was made to use BH55 only as a control interval. It would be free of intentionally introduced, suspected fluorine contaminants (i.e. Viton ${ }^{\mathrm{TM}}$ and Teflon ${ }^{\mathrm{TM}}$ ); however, the sampled gas compositions would be affected potentially by more significant communication with nearby drifts/boreholes and therefore not be reflective of the gas in the rock of the DST. All sampling of BH55 was in coordination with that conducted in $\mathrm{BH} 72$, and all samples were submitted for laboratory analyses.

After the initial field survey, the next activity was the preparation of the apparatus used to. introduce Viton $^{\mathrm{TM}}$ - and Teflon ${ }^{\mathrm{TM}}$-bearing samples into BH72. An apparatus was developed that employed a rigid push rod to position a Teflon ${ }^{\mathrm{TM}}$ sampling tube along with various Viton ${ }^{\mathrm{TM}}$ samples at a predetermined depth. Threaded rods, couplings, and 16 gauge wire milled from C276 alloy were procured. Alloy C276 was chosen because it is less reactive to corrosive environments (www.haynesintl.com/C276site/H2002CACD.htm) relative to other metals and would be much less likely to attenuate any HF signal that developed, as might occur with the use of conventional stainless steel or titanium.

Ideally, aged Viton ${ }^{\mathrm{TM}}$ and Teflon ${ }^{\mathrm{TM}}$ from one of the high temperature boreholes would need to be introduced. Although complete removal of packers from the test block was thought to be 
difficult, technicians were able to extract the entire packer assembly from BH60. Viton ${ }^{\mathrm{TM}}$ sections cut from BH60 packer 3, Viton ${ }^{\mathrm{TM}}$ sections from an unused Single Heater Test packer, and test batch sections of Viton ${ }^{\mathrm{TM}}$ (procured prior to the full production run for the DST) were wired to a 12 -foot-long section of C276 alloy push rod. An 8-foot-long section of PTFE Teflon ${ }^{\mathrm{TM}}$ tubing, recovered from BH60, was held in place with wire wrapped Viton ${ }^{\top \mathrm{M}}$. As shown in Figure 2 , a sampling port was created by positioning the Teflon ${ }^{\mathrm{TM}}$ sampling tube end at the middle, unwrapped section of push rod. The 12-foot-long Viton ${ }^{\mathrm{TM}} / \mathrm{Teflon}^{\mathrm{TM}}$ sampling string was preassembled and delivered to Alcove 5 ready for installation.

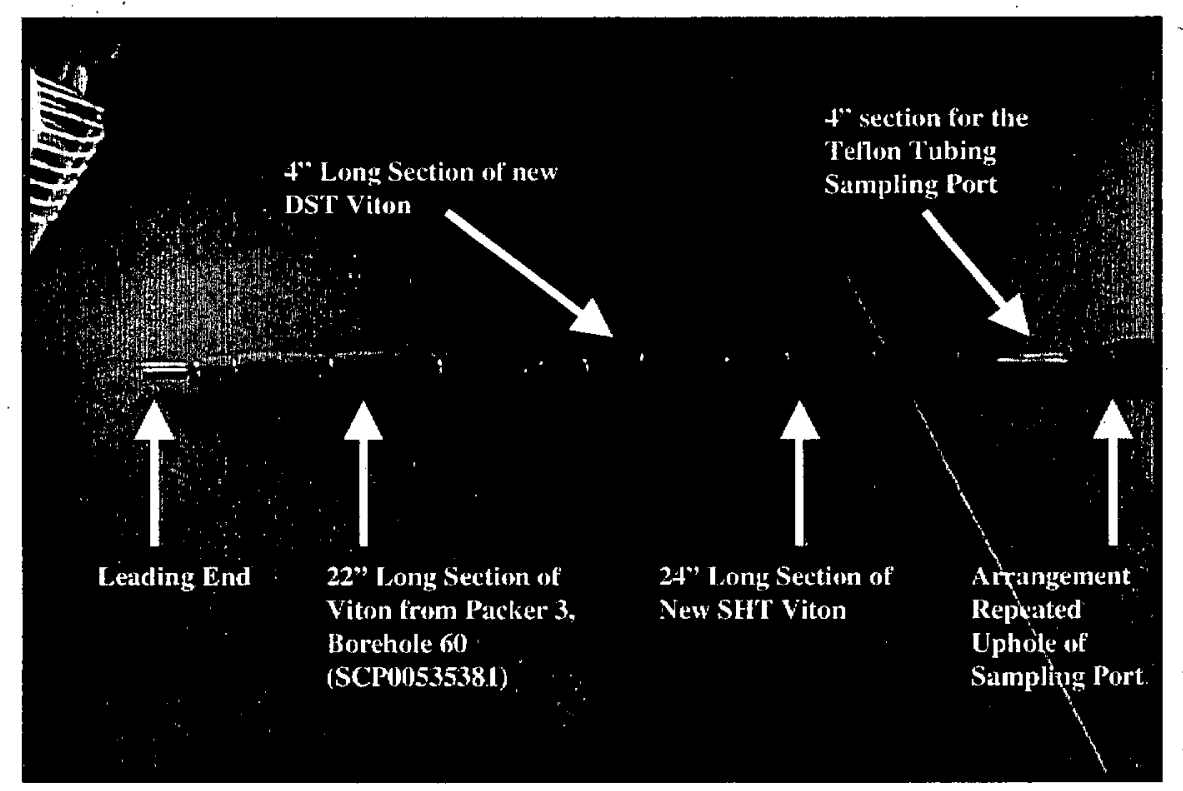

Figure 2. Photograph showing the Viton ${ }^{\top \mathrm{M}}$ sample string prior to installation in $\mathrm{BH} 72$.

Before the Viton ${ }^{\mathrm{TM}}$ sample string was installed, a baseline water sample was acquired from $\mathrm{BH} 72$. On November 26, 2001, a 100 foot length of Tygon ${ }^{\mathrm{TM}}$ tubing was flushed with about $1 \mathrm{~L}$ of deionized water. Seven segments of the $\mathrm{C} 276$ alloy push rod were used to position the tubing at a depth of 84 feet. The tubing was clamped to the first segment of push rod using C276 alloy wire. Approximately $50 \mathrm{~mL}$ of condensed water was flushed through the collection line, then $100 \mathrm{~mL}$ of baseline water was collected in 30 minutes. Field measurements were performed on the water sample to quantify $\mathrm{pH}$, temperature, and conductivity. The push rods and sampling tube were removed in preparation for installation of the Viton ${ }^{\mathrm{TM}}$ sample string.

The sampling string was installed in $\mathrm{BH} 72$ along with 6 additional 12-foot $\mathrm{C} 276$ alloy rods as shown in Figure 3. The sampling port was located at a depth of 78 feet. The 8-foot sampling string tube was connected to a 50-foot section of PTFE Teflon ${ }^{\mathrm{TM}}$ tubing that was purchased for this test. The remaining 20 feet of Teflon ${ }^{T M}$ tubing was assembled from sections removed from BH60 and connected to the end nearest the collar. Two mechanical borehole plugs were installed at the borehole collar to reduce the exchange of air with the DST Access/Observation drift.

Installation of the sampling apparatus in $\mathrm{BH} 55$ was the next experimental activity. Instead of a Teflon $^{\mathrm{TM}}$ sampling tube, a 0.375 -inch O.D. C276. alloy steel tube was employed. The tube was 
rinsed with $2 \mathrm{~L}$ of deionized water prior to installation. Seven 10-foot-3-in-long sections of tubing were connected together with compression fittings to form a 71 -foot-9-inch continuous length when installed into BH55. A pump was connected to steel alloy tubing at the collar with a short extension of Tygon ${ }^{\mathrm{TM}}$ tubing and sampling began just after noon. The pump drew only $20 \mathrm{~mL}$ of water in about 2 hours with the aid of a cold trap formed by running the Tygon ${ }^{\mathrm{TM}}$ tubing through an ice bath. Field measurements of $\mathrm{pH}$, temperature, and conductivity were also obtained. Analytical results of baseline water samples acquired from BH55 and BH72 are included in the Laboratory Analysis Section below.

Three days later, on November 29, 2001, more samples were collected from both boreholes. It only took about 10 minutes to flush the line in $\mathrm{BH} 72$ with $100 \mathrm{~mL}$ of condensed water. This borehole continued to produce abundant sample. Field measurements were performed on the $100 \mathrm{~mL}$ sample and the equipment was moved to BH55. Once again, the rate of water collection was extremely slow. Only a $13 \mathrm{~mL}$ sample was collected after 3 hours of pumping. The final samples were collected on December 5, 2001 with a similar outcome. BH72 produced $500 \mathrm{~mL}$ of water in less than an hour while BH55 remained comparatively dry.

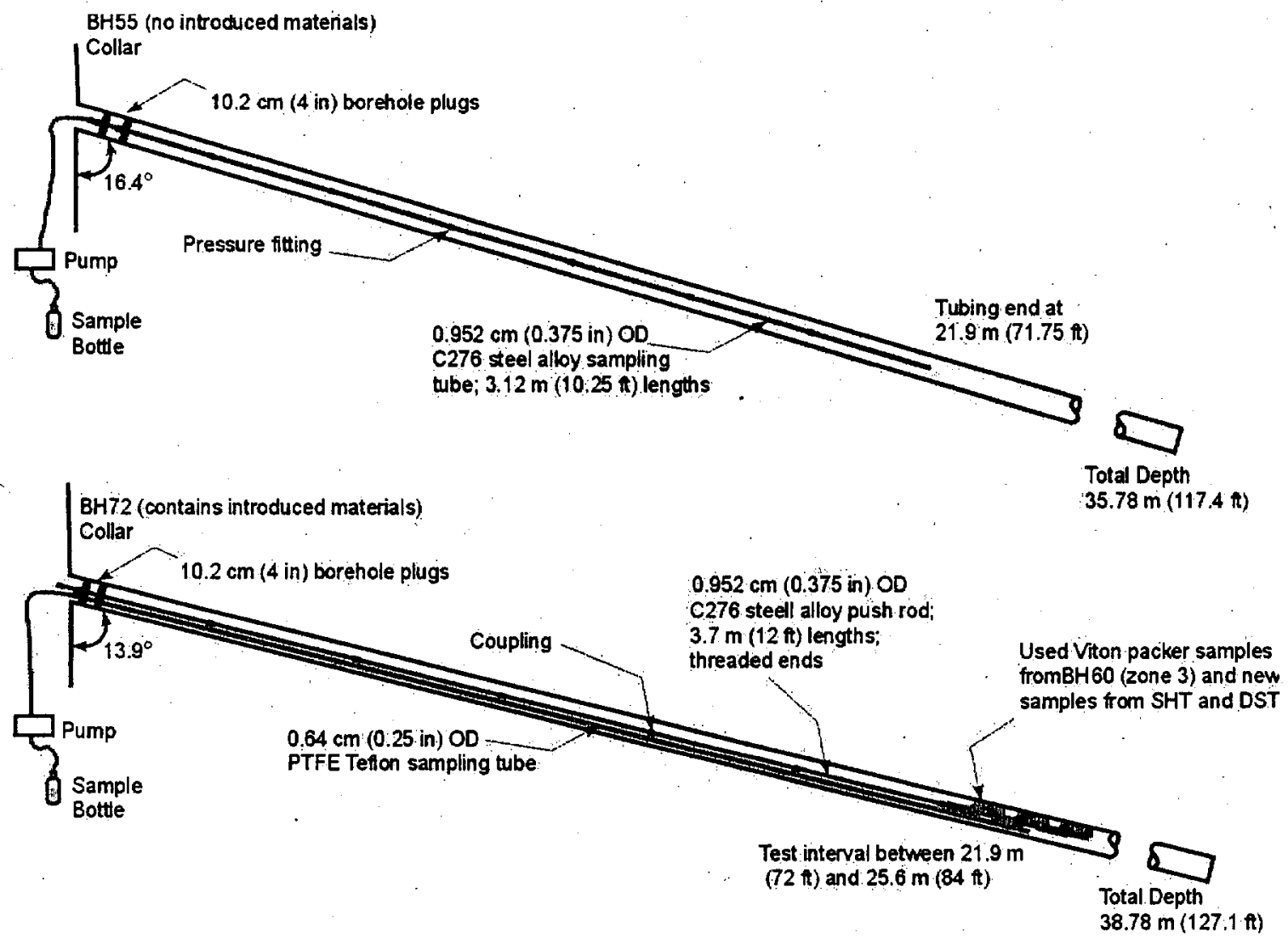

Figure 3. Schematic of the sampling apparatus installed in BH55 and BH72. 


\section{Analytical Results}

Although samples were collected for the full range of analytical tests conducted on DST waters, reporting the entire suite of analyses is beyond the scope of this report. The analyses of interest from this field study are those parameters collected at the time of sampling that are indicative of high fluoride concentrations (e.g. pH, TDS, and EC) and the analytical fluoride measured by Ion Chromatography (IC). Therefore, as with samples obtained throughout the heating phase of the DST, samples collected in the field and designated for anion testing were filtered (note: one BH55 exception) and tightly capped. Field parameters were obtained for each sample with sufficient sample volume. Values reported for $\mathrm{pH}$, total dissolved solids (TDS), and electrical conductivity (EC) were automatically corrected to ambient temperature, $\left(\sim 20^{\circ} \mathrm{C}\right)$ and documented in sample collection summaries. Samples were delivered and logged immediately at the Sample Management Facility (SMF) and priority shipped to LLNL. All samples collected during the HF field experimentation were submitted to qualified analytical laboratories for determination of fluoride content.

The summary of all field parameters (corrected to ambient temperature of $\sim 20^{\circ} \mathrm{C}$ ) and analytical fluoride values for $\mathrm{BH} 72$ (baseline and post-test samples) and BH55 (control samples) are compiled in Table 1. Additional data for BH72 (collection date: 06/28/01 and 11/8/01) are provided from sampling activities that predate the HF field study. The only differences among procedures are noted when Tygon ${ }^{\top M}$ sample tubing was used instead of C276 alloy.

The fluoride data for BH72 (including data from 6/28/01 and 11/8/01) are plotted in Figure 4. Fluoride values for samples collected before introduction of Viton ${ }^{\mathrm{TM}}$ and Teflon ${ }^{\mathrm{TM}}$ are consistent with values from other condensation samples from lower temperature zones (zones still above boiling). Fluoride is well below $1 \mathrm{ppm}$.

Table 1. Field measurements and F-content of "condensates" sampled during the HF field tests.

\begin{tabular}{|c|c|c|c|c|c|}
\hline $\begin{array}{l}\text { sample } \\
\text { identification }\end{array}$ & $\begin{array}{c}\text { SMF } \\
\text { number }\end{array}$ & $\begin{array}{c}\text { collection } \\
\text { date }\end{array}$ & $\begin{array}{l}\text { field } \\
\text { pH }^{*} \\
\end{array}$ & $\begin{array}{c}\text { E.C. / TDS } \\
(\mu \mathrm{s} / \mathrm{cm}) /(\mathrm{ppm}) \\
\end{array}$ & $\begin{array}{c}F \\
(\mathrm{mg} / \mathrm{L}) \\
\end{array}$ \\
\hline 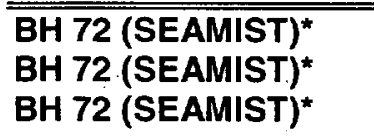 & $\begin{array}{l}\text { SPC00559475 } \\
\text { SPC00559475 } \\
\text { SPC00575228 }\end{array}$ & $\begin{array}{l}6 / 28 / 2001 \\
6 / 28 / 2001 \\
11 / 8 / 2001\end{array}$ & $\begin{array}{c}4.8 \\
4.8 \\
5.1-5.5\end{array}$ & $\begin{array}{c}15 / 9 \\
15 / 9 \\
19 / 12\end{array}$ & $\begin{array}{c}\mathrm{nd}<0.007 \\
\text { nd } \\
0.15\end{array}$ \\
\hline $\begin{array}{l}\text { BH } 72 \text { baseline } \\
\text { trip 11/26/01: VITON a }\end{array}$ & $\begin{array}{l}\text { SPC00575219 } \\
\text { ad Teflon installed }\end{array}$ & $11 / 26 / 2001$ & 5.3 & $14 / 9$ & $\mathrm{nd}<0.007$ \\
\hline $\begin{array}{l}\text { BH } 72 \text { (viton, PTFE) } \\
\text { BH } 72 \text { (viton, PTFE) } \\
\text { BH } 72 \text { (viton, PTFE) }\end{array}$ & $\begin{array}{l}\text { SPC00559478 } \\
\text { SPC01016065 } \\
\text { SPC01016066 }\end{array}$ & $\begin{array}{l}11 / 29 / 2001 \\
12 / 5 / 2001 \\
12 / 5 / 2001\end{array}$ & $\begin{array}{l}3.8 \\
3.45 \\
3.44\end{array}$ & $\begin{array}{l}41 / 25 \\
112 / 71 \\
135 / 85\end{array}$ & $\begin{array}{l}2.39 \\
7.60 \\
7.23\end{array}$ \\
\hline $\begin{array}{l}\text { BH } 55 \text { baseline } \text { b }^{\star \star} \\
\text { BH } 55 \\
\text { BH } 55\end{array}$ & $\begin{array}{l}\text { SPC00575229 } \\
\text { SPC00559479 } \\
\text { SPC01016067 }\end{array}$ & $\begin{array}{c}11 / 26 / 2001 \\
11 / 29 / 2001 \\
12 / 5 / 2001\end{array}$ & $\begin{array}{l}5.0 \\
5.2 \\
\mathrm{Na}\end{array}$ & $\begin{array}{l}21 / 13 \\
\text { na } \\
\text { na }\end{array}$ & $\begin{array}{l}1.34 \\
0.35 \\
0.08\end{array}$ \\
\hline
\end{tabular}

* sample acquired with Tygon tubing

**baseline sample acquired using C276 alloy tubing 


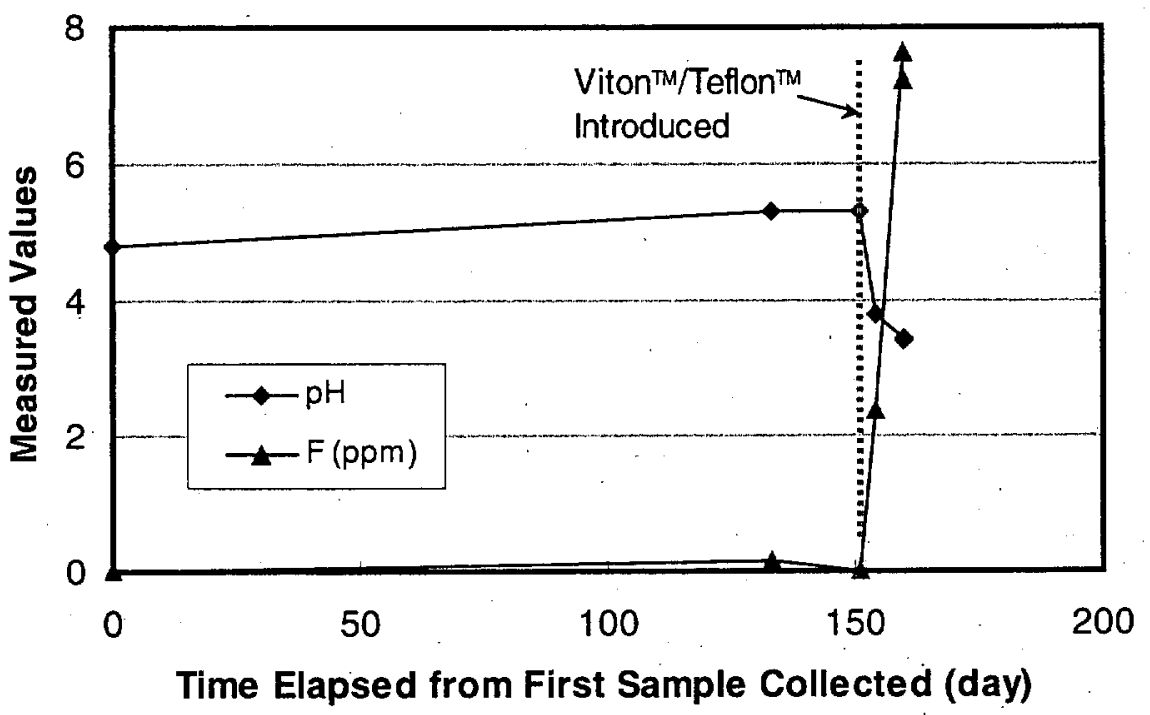

Figure 4. Fluoride and $\mathrm{pH}$ versus time for water samples acquired from BH72. Suspected Fcontaminating materials introduced after sample collection on Nov. 26, 2001.

Precision and accuracy are both $\pm 10 \%$ of the measured fluoride value.

\section{Discussion}

The field tests described were designed to assess the probability that fluoride and the low $\mathrm{pH}$ values in the steam condensates were derived from introduced materials used in the high temperature HYD zones of the DST. Aqueous analyses of the condensed sample identified as BH72 baseline were consistent with generally clean water chemistry seen from condensed steam in lower temperature boreholes. Also, the measured $\mathrm{pH}$ of 5.3 reflects similarly reported values of $\sim 4.1$ to 5.9 for other DST samples condensed from steam. After introducing the potentially contaminating materials (i.e. Viton ${ }^{\mathrm{TM}}$ and Teflon ${ }^{\mathrm{TM}}$ ) into $\mathrm{BH} 72$, subsequent samples demonstrate a decrease in $\mathrm{pH}$ from 5.3 to 3.8 within three days and finally as low as 3.4 after nine days.

Fluoride also increases from $\sim 0 \mathrm{ppm}$ in the baseline sample to $\sim 7.6$ (and 7.2) ppm during the last sample collection (nine days after introduction of the Viton ${ }^{\top M}$ and Teflon ${ }^{\top M}$ ). BH72 samples show a marked decrease in $\mathrm{pH}$ and a significant increase in $\mathrm{F}$ shortly after the installation of Viton ${ }^{\mathrm{TM}}$ and Teflon ${ }^{\mathrm{TM}}$, clearly indicative of the effect of the introduction of such materials in the high temperature zones of the DST.

The interpretation of BH55 as a control was possibly affected by some of the issues noted during the original characterization. The sampling efforts produced only minor volumes of fluid, so that dilution of the sample was necessary to have sufficient sample for the (full suite) of analyses, which cause small errors in turn to be multiplied. The sample volumes were also potentially affected by even minor contamination introduced from the sampling and/or processing. The benefit of a sampling blank for analyses was not performed. Nevertheless, the $\mathrm{pH}$ of the sample measured was in the appropriate range of lower temperature condensate samples. In Addition, the $\mathrm{F}$ concentration was under $2 \mathrm{ppm}$, below the range observed for the class of low $\mathrm{pH}$, high $\mathrm{F}$ condensates. 